\title{
Taxação Ótima e Movimentos Migratórios em Uma União Monetária
}

\author{
Carlos Eduardo Soares Gonçalves Professor do Departamento de Economia - FEA/USP
}

\begin{abstract}
RESUMO
Este artigo apresenta um modelo simples no qual parte de uma força de trabalho heterogênea tem a liberdade de migrar de um estado (ou país) atingido por um choque econômico negativo. Tem-se que um governo não-benevolente, e que objetiva simplesmente aumentar sua receita tributária, não pode desconsiderar a "restrição de participação" dos trabalhadores na hora de decidir o tamanho da alíquota de taxação do trabalho. Mostra-se que um choque de prolongada duração pode induzir alíquotas mais elevadas ou mais baixas, dependendo de quão custosa é a opção de deixar o país.
\end{abstract}

\section{PALAVRAS-CHAVE}

migração, taxação, choques

\begin{abstract}
This article presents a simple model in which a part of a heterogeneous labor force may find it optimal to flee a state (or a country) negatively affected by an adverse economic shock. Crucially, a non-benevolent government, choosing the tax rate to maximize public revenue, has to take workers' "participation constraint" into consideration. It is found that a negative shock lasting for a prolonged period might induce higher or lower tax rates, depending on how severe migration costs are.

KEY WORDS

migration, taxation, shocks
\end{abstract}

JEL Classification

F22, $\mathrm{H} 3$ I 


\section{INTRODUÇÃO}

Um aspecto interessante inerente à discussão sobre política fiscal em Uniões Monetárias - como a que há mais de 200 anos vigora entre os estados norte-americanos, ou a recente Zona do Euro na Europa - diz respeito à relação entre as decisôes de taxação dos fatores de produção (capital e trabalho) efetuadas por governos estaduais ou nacionais e as decisões de migração levadas a cabo por trabalhadores e empresários.

Como bem colocado por Eichengreen (1993) e Eichengreen e Bayomi (1993), o desejo dos países europeus de incrementar a integração socioeconômica no velho continente, motivados pela idéia de construir uma Europa mais forte e unida, ${ }^{l}$ contribuirá para tornar mais dificultosa a manipulação discricionária da política fiscal por parte dos tesouros nacionais dos países membros. Isto porque, além dos rígidos pré-requisitos fiscais que regem o chamado Pacto de Estabilidade, é de se esperar que em um ambiente de fronteiras mais abertas e com custos de migração mais reduzidos a mobilidade dos fatores de produção se elevará, tornando-os assim mais elásticos a eventuais alterações de alíquotas. O objetivo deste trabalho é caracterizar a política ótima de tributação e as decisões de migração de agentes racionais dentro de uma união monetária, que pode ser caracterizada por um conjunto de estados utilizando a mesma moeda, como nos EUA, ou por um conjunto de países, como na Europa.

Vale dizer que um governo (não-benevolente) que vise apenas maximizar a arrecadação tributária a valor presente - com o simples objetivo de expandir sua restrição orçamentária e assim incrementar seus gastos - não pode desconsiderar o fato de que os detentores dos fatores taxados buscarão escapar à expropriação de sua riqueza, seja por meio de envio de seu capital para o exterior (no caso dos detentores de capital), seja simplesmente migrando de país (no caso dos trabalhadores).

Há na literatura vários artigos que tratam o problema de capital flight acima apresentado, sendo Persson e Tabellini (1992) o mais diretamente relaciona-

1 Para críticas ao argumento de que maior integração econômica levará a um maior e mais harmoniosa integração política, ver ALESINA et al. (2000) e FELDSTEIN (1997). 
do à questão da taxação ótima do capital em Uniões Monetárias. No entanto, pouca atenção tem sido dada à possibilidade de movimentos migratórios da força de trabalho originários de alterações de política fiscal e/ou incidência de choques negativos idiossincráticos sobre um determinado estado ou país. As exceções são os modelos baseados na lógica de "votar com seus próprios pés”, como em Tiebout (1954) e Epple e Romer (1991), onde indivíduos com rendas heterogêneas buscam jurisdiçôes - caracterizadas por diferentes pares (tributação; gastos do governo) - nas quais seu bem-estar seja maximizado. Vale dizer que o presente artigo apresenta uma lógica similar, com a crucial diferença de que, aqui, a heterogeneidade dos agentes refere-se à sua facilidade relativa em migrar (além disto, a formulação geral do corrente modelo é bastante distinta daqueles).

No que tange à ligação do modelo apresentado com a realidade empírica, há evidências de que a força de trabalho de fato reage à incidência de choques negativos locais via migração interestadual dentro das fronteiras de seu país. É importante também ressaltar que, apesar de alguns achados empíricos atestarem a baixa mobilidade do fator trabalho entre os países europeus (EICHENGREEN 1991; EICHEGREEN \& BAYOMI 1993; OBSTFELD \& PERI, 1998), há possibilidade de que a mobilidade ex-post dos trabalhadores (após a implementação da união) seja mais significativa que a encontrada nas séries históricas, tornando a questão da migração mais relevante no que diz respeito a decisões de política fiscal.

Levando este aspecto em consideração, o presente artigo propõe um modelo que considera explicitamente a decisão de migração das famílias entre os estados (ou países) que constituem uma união monetária. Aqui, o único objetivo do governo será o de maximizar sua arrecadação tributária - seja porque ele consegue desviar parte da arrecadação para seu próprio bolso, seja para incrementar gastos e prestígio - em um mundo sem capital e sem a disponibilidade de impostos lump-sum. A idéia é estudar como a presença de choques idiossincráticos (temporários ou permanentes) incidentes sobre a renda dos trabalhadores de uma determinada economia deve afetar as decisões ótimas de tributação (do governo) e de migração (dos trabalhadores). 
O modelo ainda realisticamente contempla a possibilidade de que diferentes trabalhadores apresentem custos heterogêneos de migração. Tal característica permitirá que, por exemplo, trabalhadores estrangeiros - indivíduos com poucos vínculos sentimentais em relação ao país onde residem - tenham mais facilidade em migrar quando a renda líquida do trabalho se contrair do que trabalhadores efetivamente nascidos no país afetado. $\mathrm{O}$ mesmo raciocínio vale para indivíduos com elevado capital humano, que falam diversos idiomas etc.

Deveras interessante é o fato que choques negativos de maior magnitude têm, neste modelo, efeitos dúbios sobre a decisão de taxação do governo, apesar de inequivocamente aumentarem a taxa de migração em equilíbrio. O motivo não é difícil de entender: se, por um lado, salários mais baixos (devido à incidência do choque negativo) tendem a aumentar a alíquota ótima a ser cobrada pelo governo - dado que o mesmo objetiva manter o maior nível de gastos possível (efeito-renda); por outro, este mesmo choque negativo aumenta a parcela da sociedade que se beneficiaria em migrar para um país vizinho não afetado. Tal fato atenuaria a "voracidade tarifária" do governo, pois este passaria a temer que uma elevação de alíquotas ocasionasse um encolhimento muito significativo de sua base de arrecadação (efeitosubstituição). Como demonstrado adiante, o efeito-renda mais que compensará o efeito-substituição quando o custo médio de migração for suficientemente elevado.

Outro resultado apresentado enfatiza quais as respostas das variáveis endógenas - migração e taxação - a mudanças no grau de permanência dos choques. Conclui-se que choques de caráter mais permanente podem levar o governo a aumentar a alíquota de impostos ao mesmo tempo que induzem uma maior migração por parte dos trabalhadores. Note-se que, a priori, seria intuitivo conjecturar que choques mais duradouros, ao aumentar a propensão a migrar da força de trabalho, inibiriam a vontade do governo de efetuar aumentos no imposto sobre os salários. Isto, no entanto, não acontecerá caso os custos de migração estejam acima de um certo patamar. Dois são os motivos: primeiro, quando a mobilidade do fator trabalho não é muito alta, o efeito de um aumento na duração do choque sobre a disposição a migrar será, apesar de positivo, modesto; segundo, choques de caráter 
mais permanente implicam fortes quedas na arrecadação do governo a valor presente. Diante de uma queda indesejável na arrecadação, e percebendo a baixa mobilidade do fator trabalho, a decisão do governo é inequívoca: elevar a alíquota tributária sobre aqueles que permanecem no país. Por fim, são analisados os efeitos de uma diminuição nos custos fixos de migração ${ }^{2}$ sobre os valores de equilíbrio do imposto e da taxa de migração. Como esperado, custos de migração mais modestos aumentam a taxa de migração em equilíbrio e, justamente por afetarem positivamente a mobilidade do fator trabalho, levam a alíquotas de taxação mais baixas.

Este artigo apresenta, além desta introdução, 3 outras seções. Na seção 1 é apresentado um modelo de migração ótima onde não há taxação do governo; a seção 2, parte principal do trabalho, estuda as decisões endógenas de taxação do governo e de migração dos trabalhadores; finalmente, a última seção conclui o artigo.

\section{UM MODELO SEM GOVERNO}

Para facilidade de exposição, antes de se entrar na análise da determinação conjunta (e endógena) da taxa de migração e da alíquota tributária incidente sobre os salários é apresentado, nesta seção, um modelo simples de migração em uma economia sem governo. Dado isto, a única força que induzirá uma parcela da população nacional a migrar para o exterior é a presença de um choque negativo exógeno sobre a renda do trabalho. Assume-se um modelo de vida infinita, onde o mencionado choque acontece no início dos tempos.

\subsection{Trabalhadores, Choques e Custos de Migração}

O modelo assume trabalhadores neutros ao risco, mas, como ficará claro mais adiante, funções de utilidade estritamente côncavas apenas reforçariam as conclusões do artigo.

2 Estes são os custos comuns que incidem sobre todos os trabalhadores que decidem migrar. Muitos economistas e líderes políticos europeus acreditam que tais custos devem diminuir nas próximas décadas com a diminuição de barreiras à imigração e a maior harmonização das instituiçóes que regem a dinâmica dos mercados de trabalho. 
Denominando de $U_{i}$ a utilidade do trabalhador que opta por não migrar e $U_{i}^{*}$ a do trabalhador que deixa o país após a ocorrência de um choque negativo, tem-se que:

$$
U_{i}=\int_{0}^{T} \alpha \cdot w \cdot e^{-\beta \cdot t} \cdot d t+\int_{T}^{\infty} w \cdot e^{-\beta \cdot t} \cdot d t \quad \text { e } \quad U_{i}^{*}=\int_{0}^{\infty} w \cdot e^{-\beta \cdot t} \cdot d t-\theta^{i} \cdot c^{3},
$$

Onde:

$\alpha \in[0,1]:$ representa a magnitude do choque negativo sobre os salários domésticos;

$T$ : é o período de duração do choque adverso;

$\beta$ : é a taxa de desconto;

$\theta^{i}$ : é o parâmetro que representa as características individuais de cada trabalhador, as quais tornam mais ou menos custosa a decisão de migrar de país. Assume-se, inicialmente, que $\theta$ é distribuído na população (normalizada para tamanho 1) de acordo com uma função de distribuição acumulada genérica e diferenciável, $F(\theta)$;

$c$ : é custo fixo de migrar que atinge todos os trabalhadores que optam por deixar o país. Note-se, entretanto, que este custo afeta diferentemente cada um deles (por estar multiplicado pelo parâmetro de heterogeneidade). No decorrer deste artigo, quedas em $c$ devem ser interpretadas como diminuiçỗes das barreiras legais à migração da força de trabalho entre países (possivelmente após a implantação de uma união monetária).

3 A hipótese de que o salário real no exterior é igual ao salário real nacional em períodos de normalidade não afeta qualitativamente os resultados do modelo. 


\subsection{Migração Ótima e Estática Comparativa}

Estando ausente a taxação sobre a renda do trabalho, é fácil perceber que um indivíduo genérico $i$ considerará lucrativa a decisão de migrar se e somente se:

$$
U_{i}^{*} \geq U_{i} \Rightarrow \theta^{i} \leq \frac{\left(1-e^{-\beta . T}\right)}{\beta . c} .(1-\alpha) . w
$$

Denominando $\theta^{\lim }$ o valor de $\theta^{i}$ que torna (1) uma igualdade, tem-se que a parcela da população que permanece no país após a ocorrência do choque é dada por $1-F\left(\theta^{\lim }\right)$, enquanto que a taxa de migração pode ser expressa por $F\left(\theta^{\lim }\right)$.

Proposição 1: Uma queda no custo fixo de migração $c$ aumenta a parcela da população que deixa o país após a ocorrência de um choque negativo.

Prova: $\frac{\partial F}{\partial c}=-f(.) \cdot \frac{\left(1-e^{-\beta . T}\right)}{\beta \cdot c^{2}} \cdot(1-\alpha) \cdot w<0$

Proposição 2: A taxa de migração cresce com a magnitude e com o grau de permanência do choque adverso.

Prova: $\frac{\partial F}{\partial \alpha}=-f(.) \cdot \frac{\left(1-e^{-\beta . T}\right)}{\beta . c} . w<0$ e $\frac{\partial F}{\partial T}=f(.) \cdot \frac{e^{-\beta . T}}{c} \cdot(1-\alpha) \cdot w>0^{4}$

\section{MIGRAÇÃO E POLÍTICA FISCAL}

Nesta seção acrescenta-se à estrutura básica delineada na seção 1 a presença de um governo não-benevolente cujo objetivo é puramente maximizar gastos públicos, seja por status, seja porque ele é capaz de desviar parte destes recursos para benefício próprio. Assumindo que o mesmo é neutro ao risco e, portanto, indiferente em relação ao padrão temporal de seu consumo, seu problema passa a ser simplesmente maximizar a arrecadação tributária a valor presente levando em consideração os incentivos a migrar da força de tra-

4 Note que valores mais baixos de $\alpha$ correspondem a choques de maior magnitude. 
balho. Para evitar o aparecimento de problemas de inconsistência temporal, assume-se que a escolha do governo sobre o valor de $\tau$ ocorre após a incidência do choque negativo, mas previamente à decisão de migração dos trabalhadores.

Vale dizer que caso o governo conhecesse perfeitamente o parâmetro que reflete as características individuais de cada residente do país (os $\theta^{i}$ ), o mesmo seria capaz de extrair todo o "excedente do consumidor" da força de trabalho, elevando a alíquota individualizada até o ponto em cada trabalhador se tornasse indiferente entre permanecer ou não dentro das fronteiras nacionais. Dado que tal hipótese é implausível devido à exigência informacional requerida, será assumido que a taxação sobre os salários $(\tau)$ não pode ser indexada ao parâmetro $\theta^{i}$ e deve incidir uniformemente sobre todos os indivíduos.

\subsection{Migração e Taxação Ótimas}

Antes de postular o problema de maximização do governo, é necessário lembrar que sendo a renda do trabalho agora parcialmente apropriada pelo ente público, a nova expressão que define $\theta^{\lim }$ passa a ser dada por :

$$
\theta^{\lim }=\frac{\left[1-\alpha(1-\tau)-(1-\tau) \cdot(1-\alpha) \cdot e^{-\beta T}\right] \cdot w}{\beta . c}
$$

O problema do governo é então escolher $\tau$ com o objetivo de maximizar $U^{G}=\int_{0}^{\infty} \tau \cdot w \cdot\left(1-F\left(\theta^{\lim }\right) \cdot e^{-\beta \cdot t} d t\right.$, sujeito a $(2)$.

A condição de primeira ordem desta maximização é dada por:

$$
(1-F) \cdot w-\tau \cdot w \cdot \frac{\partial F}{\partial \theta^{\lim }} \cdot \frac{\partial \theta^{\lim }}{\partial \tau}=0
$$

Vale notar que a expressão acima define, implicitamente, a taxação ótima praticada pelo governo não-benevolente. Rearranjando esta condição e empregando (2), chega-se facilmente a: 


$$
w .\left(1-F\left(\theta^{\lim }\right)\right)=\frac{\left(\alpha+(1-\alpha) \cdot e^{-\beta . T}\right)}{\beta . c} \cdot \partial F\left(\theta^{\lim }\right) / \partial \theta^{\lim } \cdot \tau . w
$$

A equação acima tem uma interpretação bastante clara: o lado esquerdo de (3’) é simplesmente o benefício marginal, em termos de maior arrecadação, que decorre de uma elevação da alíquota no valor de uma unidade. Já o lado direito representa o custo marginal esperado desta decisão.

\subsection{Um Exemplo: Distribuição Uniforme}

Para se ganhar mais intuição em relação as decisões ótimas de migração e taxação é interessante especializar a função de densidade $f(\theta)$. Assumindo uma distribuição uniforme com $\theta \in[0 ; \bar{\theta}]$, e adotando a inócua normalização $w=1$, a condição de primeira ordem ( $\left.3^{\prime}\right)$ pode ser reescrita de modo a explicitar-se $\tau$ como:

$$
\tau=\frac{1}{2} \cdot\left[\frac{2 . \beta . c \cdot\left(\frac{\bar{\theta}}{2}\right)-(1-\alpha) \cdot\left(1-e^{-\beta . T}\right)}{\alpha+(1-\alpha) \cdot e^{-\beta T}}\right]
$$

Como a média da distribuição uniforme é $\frac{\bar{\theta}}{2}$, o termo $c .\left(\frac{\bar{\theta}}{2}\right)$ nada mais é que o custo médio de migração. Observando a equação (4) é tácil ver que a alíquota de taxação é menor para valores mais baixos deste custo médio. Em outras palavras, quando a mobilidade do fator trabalho é elevada, o governo é obrigado a taxar mais moderadamente os salários dos residentes sob o risco de vê-los abandonar o país. 
Proposição 3: A relação entre a intensidade do choque e a alíquota de taxação é dúbia. Choques mais severos só induzirão o governo a aumentar a alíquota de taxação quando o custo médio de migração for maior que $\frac{1}{2 \cdot \beta}$.

Prova: $\operatorname{sign} \frac{\partial \tau}{\partial \alpha}=-\operatorname{sign}(\beta . c . \bar{\theta}-1)$

Mais uma vez, o fato de o sinal da derivada $\frac{\partial \tau}{\partial \alpha}$ não ser inequívoco deve-se à presença simultânea de efeitos renda e substituição que agem em sentidos opostos. Quando a base de arrecadação tem baixa mobilidade, prevalece o efeito-renda, e choques mais severos levam o governo a aumentar a taxação sobre os salários. Já quando a mobilidade é alta devido ao baixo custo médio de migração, a opção ótima do governo - quando confrontado com um choque de magnitude relevante - é diminuir as alíquotas com vistas a impedir uma contração indesejada da sua base de tributação.

Proposição 4: A alíquota de tributação será positivamente correlacionada com a duração do choque se o custo médio de migração for superior a $\frac{1}{2 \cdot \beta}$.

Prova: $\operatorname{sign} \frac{\partial \tau}{\partial T}=\operatorname{sign}(\beta . c \bar{\theta}-1)$

A possibilidade, aparentemente contra-intuitiva, de observar-se um equilíbrio com choques permanentes e alta taxação tem uma justificativa simples: a diminuição na arrecadação do governo, devido ao empobrecimento da economia em bases permanentes, naturalmente eleva sua disposição de apropriar-se de uma parcela maior da renda dos trabalhadores. No entanto, a decisão de aumentar a alíquota para recompor a receita agregada perdida não ocorrerá caso haja elevada facilidade entre os trabalhadores em migrar para outra jurisdição (fugindo, assim, do aumento da carga tributária). 


\section{COMENTÁRIOS FINAIS}

Resumidamente, a principal conclusão deste artigo é de que para se entender a decisão de um governo não-benevolente de elevar ou diminuir a alíquota de taxação após a ocorrência de uma queda na renda dos trabalhadores de sua jurisdição é preciso atentar-se para a magnitude da mobilidade do fator trabalho. Caso migrar seja (ou venha a se tornar) uma atividade relativamente pouco custosa, em equilíbrio, a voracidade tarifária do soberano será restringida e a alíquota de taxação final será mais amena.

Por fim, é válido destacar uma possível extensão futura: o modelo aqui apresentado não considera explicitamente a possibilidade de que os diversos países (ou estados) desenhem suas políticas de taxação ótima levando em consideração as opções estratégicas disponíveis a jurisdições vizinhas (apesar de considerar as decisões estratégicas dos trabalhadores). $\mathrm{O}$ equilíbrio de Nash de um jogo não-cooperativo entre distintas jurisdições - que objetivam atrair trabalhadores estrangeiros e assim engrossar sua base de arrecadação - levaria, no entanto, a resultados semelhantes aos aqui apresentados no que tange à escolha da variável $\tau$. Isto porque, neste caso, cada governo resolveria seu problema de maximização tomando a escolha do outro como dada e, portanto, a condição de primeira ordem (3) seria apenas levemente modificada. Mais precisamente, o salário de reserva (aquele vigente na jurisdição vizinha) do trabalhador doméstico passaria para $\left(1-\tau^{*}\right) . w$, diminuindo a taxa de migração e elevando a alíquota de tributação doméstica, ceteris paribus.

Neste novo arcabouço, a ocorrência de um choque negativo no país doméstico levaria a um aumento da taxação no país estrangeiro devido à atratividade relativa (em termos de salários mais elevados) deste último. Este incentivo à elevação de tarifas provavelmente levaria a menores taxas de migração em equilíbrio. Muito interessante e o fato de que o nível da alíquota de taxação é subotimamente baixo do ponto de vista dos governos nãobenevolentes neste jogo não-cooperativo. Isto porque os ganhos individuais inerentes a uma escalada tarifária são menores que os benefícios coletivos, já que uma elevação simultânea de alíquotas - ao conter possíveis fluxos migratórios da base de arrecadação de cada país - abriria espaço para maior 
expropriação da riqueza dos trabalhadores por parte dos governos não-benevolentes. Assim, como em Rogoff (1985), cooperação internacional entre governos pode, também neste modelo, ser indesejável sob a ótica da população.

\section{REFERENCIAS}

ALESINA, Alberto; BARRO, Robert; TENREYO, Silvana. Optimal currency areas. NBER WP 9072, July 2002.

ALESINA, Alberto; SPOLAORE, Enrico; WACZIARG, Romain. Economic integration and political desintegration. American Economic Review, December 2000.

EICHENGREEN, Barry. Is Europe an optimal currency area? NBER WP3579, January 1991.

. European Monetary Unification. Journal of Economic Literature, p. 1321-1357, September 1993.

EICHENGREEN, Barry; BAYOMI, Tamim. Shocking aspects of European Monetary Unification. In: The transition to economic and Monetary Union in Europe. Cambridge University Press, 1993.

EPPLE, D.; ROMER, T. Mobility and redistribution. Journal of Political Economy, 99, p. 828-858, 1991.

FELDSTEIN, Martin. The political economy of the European economic and Monetary Union: political sources of an economic liability. Journal of Economic Perspectives, v. 11, p. 23-42, Fall 1997.

OBSTFELD, Maurice; PERI, Giovanni. Asymmetric shocks: regional non-adjustment and fiscal policy. Economic Policy, p. 207-259, 1998.

PERSSON, Torsten; TABELLINI, Guido. The politics of 1992: fiscal policy and European integration. Review of Economic Studies, 59, p. 689-701, 1992.

ROGOFF, K. Can international monetary cooperation be counterproductive? Journal of International Economics, 18, p. 199-217, may 1985.

TIEBOUT, C. A pure theory of local expenditures. Journal of Political Economy, 64, p. 416-424, 1954.

Email: cesg@usp.br, tel: 30916062. Agradeço a Mauro Rodrigues e aos pareceristas anônimos por seus interessantes comentários.

(Recebido em maio de 2003. Aceito para publicação em maio de 2004). 